\title{
Mediastinal Lymph Node Dissection
}

National Cancer Institute

\section{Source}

National Cancer Institute. Mediastinal Lymph Node Dissection. NCI Thesaurus. Code

C139566.

A surgical procedure in which all or most all of the lymph nodes are removed from the mediastinum. 